\title{
(t) \\ MYRIAN VERAS BAPTISTA: MESTRA APAIXONADA, SONHADORA E COMBATIVA!
}

\author{
Ademir Alves da Silva ${ }^{1}$ \\ Maria Liduína de Oliveira e Silva² \\ Maria Manoela Valença ${ }^{3}$
}

Submetido: 15/12/2015.

Aceito: 16/12/2015.

Com muita alegria aceitamos o convite de José Fernando Siqueira da Silva, editor da Temporalis, para escrever sobre nossa memorável professora Myrian Veras Baptista. Uma verdadeira honra! Esta homenagem é e será sempre expressão do reconhecimento e de eterna gratidão por sua engajada trajetória profissional e participação na história do Serviço Social brasileiro.

Myrian Veras Baptista nasceu no dia 4 de março de 1931, na pequena cidade de Monte Aprazível, no interior do estado de São Paulo, filha do casal Milton Spencer Veras e Margarida Busse Veras. Durante sua mocidade, morou no bairro da Pompeia, em São Paulo. Viveu também nas cidades de Ponta Grossa, Curitiba e Londrina, no estado do Paraná.

Em 1955, casou-se com Milton Pizante Baptista e, dessa união, nasceram os filhos: Celso, Helena, Renato e Plínio.

\footnotetext{
1 Assistente social e coordenador do Programa de Estudos Pós-graduados em Serviço Social da Pontifícia Universidade Católica de São Paulo (PUC-SP).

2 Assistente social e docente do curso de Serviço Social da Universidade Federal de São Paulo (UNIFESP).

3 Assistente social e diretora do Centro de Estudos e Editora Myrian Veras Baptista.
} 


\section{temporollis}

Graduou-se em Serviço Social em 1954, pela então Escola de Serviço Social, mais tarde agregada à Pontifícia Universidade Católica de São Paulo (PUC-SP), onde realizou seu doutoramento em Serviço Social.

Ao ingressar ${ }^{4}$ na PUC-SP, em $1^{\circ}$ de março de 1974, Myrian passou a atuar no Curso de Graduação em Serviço Social e, posteriormente, assumiu responsabilidades docentes no Programa de Estudos Pós-graduados em Serviço Social, do qual foi vice-coordenadora, no período de 1987-1989, e coordenadora, no período de 1989-1991; dedicando 40 anos de sua vida ao ensino, à pesquisa e à orientação de dissertações de mestrado e teses de doutorado. Implantou, no âmbito do Programa de Pós-Graduação em Serviço Social da PUC-SP, o Núcleo de Estudos e Pesquisas sobre Criança e Adolescente (NCA), do qual foi coordenadora. Colaborou direta e intensamente para a implantação do Doutorado em Serviço Social da PUC-SP.

Fundou a Veras Editora e a Associação dos Pesquisadores de Núcleos de Estudos e Pesquisas sobre Criança e Adolescente (NECA). Essas iniciativas externas, mas relacionadas às atividades na PUC-SP, evidenciam o vigor e a expressividade de suas contribuições às áreas acadêmica e profissional do Serviço Social. Myrian integrou, ainda, a direção do então Conselho Regional de Assistentes Sociais (CRAS) 9 $9^{a}$ Região, atual Conselho Regional de Serviço Social (CRESS), no período de 1978 a 1981. Foi uma das principais idealizadoras da Revista Serviço Social \& Sociedade da Cortez Editora.

Sua trajetória profissional representa importante contribuição na formação de gerações de docentes, pesquisadores e gestores de políticas sociais. Seu Currículo Lattes registra a orientação de 112 dissertações de mestrado, 37 teses de doutorado e dois estágios de pósdoutorado, bem como a participação em bancas de defesa de 62 dissertações de mestrado e 21 teses de doutorado. Considerando-se apenas o período mais recente de sua trajetória acadêmica, foi membro de vinte bancas de concursos públicos e comissões julgadoras e participou, inclusive como organizadora, de cerca de cinquenta eventos. Publicou vários livros, capítulos de livros e artigos, além de numerosas produções técnicas, e exerceu atividades de assessoria e consultoria.

4 Este e os próximos quatro parágrafos estão baseados no texto-homenagem a Myrian Veras Baptista, de autoria de Ademir Alves da Silva, publicado no jornal PUCVIVA, São Paulo: APROPUC, de 28 de setembro de 2015, p. 4. 
Sua trajetória profissional identifica-se com a história do Serviço Social brasileiro e latino-americano por sua presença e protagonismo no movimento de renovação da área, com expressiva produção acadêmica e científica sobre objetos como a teoria e a prática do Serviço Social, a metodologia da investigação científica, o planejamento social e estratégico, a história e o papel da Pós-graduação em Serviço Social e, especialmente, as políticas públicas voltadas para a criança e o adolescente.

Como expressão do reconhecimento, da admiração e do carinho de alunos, professores e outros profissionais, foi homenageada no evento Legado do NCA - A Unidade Teoria-Prática em mais de Vinte Anos de Pesquisas e Ações Políticas na Defesa dos Direitos da Criança e do Adolescente, realizado no TUCARENA-PUC-SP, em 21 de agosto de 2014.

Myrian compartilhava com as pessoas à sua volta, sonhos e projetos, fazendo escolhas para construir coletivamente as lutas e a história social das pessoas e da profissão. A generosidade, o respeito às diferenças e o trabalho político eram permanentes em suas ações cotidianas nas relações interpessoais e profissionais.

De muitos sonhos e projetos, foi marcadamente uma mulher de múltiplas ações e realizações, seja no âmbito da formação crítica de novas e maduras gerações, seja no cotidiano profissional de resistência nas lutas pelos direitos humanos e por justiça social. Carregava consigo a esperança de que, um dia, crianças e adolescentes, filhos de pais e mães da classe trabalhadora, pudessem estudar, brincar, ter saúde, alimentação, segurança, lazer e cultura, sendo bem cuidados e amados. E que convivessem com adultos e famílias protetoras que, assegurado o acesso a seus direitos sociais, fossem seres sociais felizes e livres da desigualdade social, de gênero e étnico-racial. Esse sonho revolucionaria a humanidade!

De presença forte, generosa, solidária, produtiva, combativa, comprometida com o projeto profissional, detentora de sabedoria incomum, foi muito além: tornou-se referência permanente para o Serviço Social, por seu legado histórico.

O que herdamos de Myrian Veras Baptista? Ela nos deixa um grande legado de pensamento e ação, sempre pautados em suas principais características: paixão, indignação, resistência e comparti- 


\section{temporalis}

Ihamento.

Esse legado expressa-se, principalmente, pelo fato de ter sido uma das pioneiras no processo de fundação da Pós-graduação em Serviço Social no Brasil, com marcante protagonismo nessa área de conhecimento na América Latina e na Europa, especialmente em Portugal.

Sua obra constitui referência no planejamento social na área do Serviço Social, por ela concebido como um processo político que exige intencionalidade e instrumentação, pautado em um novo sentido de competência. Em suas palavras: "[...] além da competência teórico-prática e técnico-operativa, há que ser desenvolvida uma competência ético-política" (BAPTISTA, 2015, p. 18).

Atuante nas políticas, programas e projetos sociais e na pesquisa e produção de conhecimento, mantinha incansável preocupação com o significado social da prática profissional da(o) assistente social, participando ativamente das denúncias contra as injustiças e omissões do Estado brasileiro quanto às políticas sociais, especialmente na área da infância e adolescência.

Estudiosa e apaixonada alertava para os riscos da dicotomia entre teoria e prática. Como sempre dizia: "[...] o saber se acantonou na academia e o não saber, na prática" (BAPTISTA; BATTINI, 2014, p. 7).

No decorrer de sua atuação no NCA-PUC-SP, foi possível conviver com a Myrian compromissada, íntegra e honesta em suas idéias e convicta de suas posições que, em diversas situações, expressaram sua capacidade de desobediência ${ }^{5}$ ao resistir, sempre que necessário, às regras institucionais, de modo a garantir que o Núcleo não ferisse os princípios que devem reger uma Universidade: liberdade de expressão, autonomia e democracia.

Myrian agregou à Editora Veras, em 2010, um Centro de Estudos. Hoje, Centro de Estudos e Editora Myrian Veras Baptista que tem como proposta gerar e difundir conhecimentos e metodologias para

5 Expressão utilizada por Maria Manoela Valença durante sua fala no evento Legado do NCA - A Unidade Teoria-Prática em mais de Vinte Anos de Pesquisas e Ações Políticas na Defesa dos Direitos da Criança e do Adolescente, realizado no TUCARENAPUC-SP, em 21 de agosto de 2014. 


\section{tempordils}

o aprimoramento, a renovação e articulação das políticas na área da seguridade social e de suas práticas, com o objetivo central de manter uma estrutura coletiva de apoio à investigação, produção intelectual e formação. Por esse motivo, o Centro abrigará, conforme sua recomendação, o acervo constituído por livros, vídeos e documentos que pertenceram à professora Myrian ou foram por ela produzidos.

A dedicação a esse projeto pessoal e profissional foi observada na forma pela qual continuou compartilhando e definindo as ações da Veras, mesmo com as atividades reduzidas, devido ao agravamento do seu estado de saúde, até o seu falecimento em 19 de setembro de 2015.

Myrian Veras Baptista deixa para a comunidade acadêmica e profissional do Serviço Social, exemplar e bela história de vida humana e profissional. De sessenta e um anos de atuação profissional, Myrian nos deixa um imensurável legado que, no conjunto, revela sua envergadura como pesquisadora, intelectual e formadora, sob os princípios fundados no compromisso ético-político e teórico-metodológico e na simplicidade humana.

\section{Referências}

BAPTISTA, M. V. Planejamento social: intencionalidade e instrumentação. 3. ed. São Paulo: Veras, 2015.

; BATTINI, O. A prática profissional do assistente social. 2. ed. São Paulo: Veras, 2014.

SILVA, A. A. Myrian Veras Baptista. Texto-homenagem. Jornal PUC-VIVA, São Paulo, 28 de setembro de 2015, p. 4. 


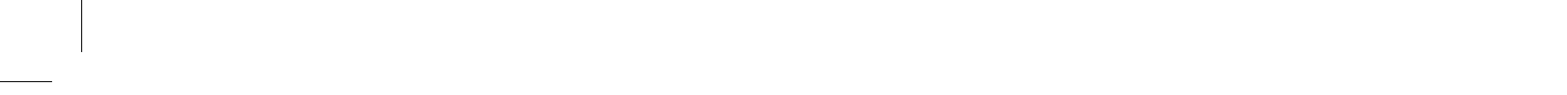

